\title{
Supporting Information \\ for \\ Identification of a Molecular Recognition Role for the Activation Loop \\ Phosphotyrosine of the Src Tyrosine Kinase
}

Elizabeth J. Videlock, Victor K. Chung, Justin M. Hall, John Hines, Christina M. Agapakis and David J. Austin*

Department of Chemistry, Yale University, New Haven, CT 06520

\section{Contents (10 pages)}

MEDIA AND REAGENTS.. .1

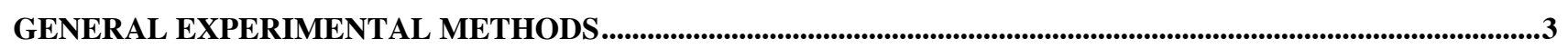

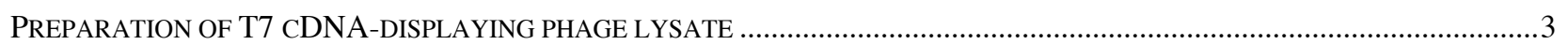

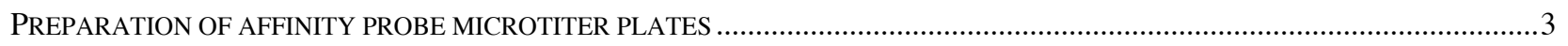

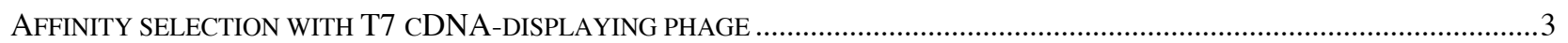

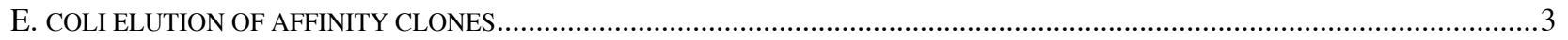

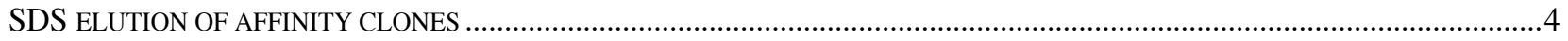

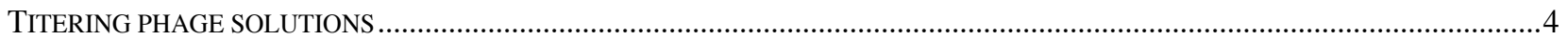

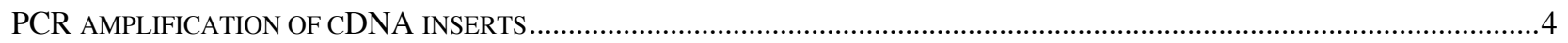

CDNA PHAGE DISPLAY SELECTION WITH THE BIO-PYTAR PEPTIDE PROBE...................................................5

SCREENING AND VALIDATION OF PHAGE FROM THE BIO-PYTAR AFFINITY SELECTION........................5

SEQUENCE IDENTIFICATION OF THE P85 PI3K N-TERMINAL SH2 CDNA PHAGE CLONE ............................6

SUPPLEMENTARY FigURE 2. DNA SEQUENCE VERIFICATION FOR P85 PI3K N-TERMINAL SH2 PHAGE CLONE...................6

PYTAR PROBE DEPENDENT PHAGE BINDING ASSAY AND INHIBITION..........................................................6

SUPPLEMENTARY TABLE 1. PARAMETER VALUES COMPUTED FROM THE BIO-PYTAR PROBE-DEPENDENT BINDING ASSAY FOR THE P85 PI3K N-terminal SH2 DOMAIN PHAGE. .............................................................................

PEPTIDE AFFINITY CHROMATOGRAPHY WITH BIO-PYTAR AND NIH 3T3 CELL LYSATE ..........................8

CO-IMMUNOPRECIPITATION AND INHIBITION OF SRC BINDING WITH $\alpha$-PI3K ANTIBODY ......................8

MUTAGENESIS OF SRC-Y527F TO FORM THE SRC-Y416F,Y527F DOUBLE MUTANT.......................................9

SUPPLEMENTARY FIGURE 3. SEQUENCE VERIFICATION OF THE SRC-Y416F,Y527F DOUBLE MUTANT. TRANSLATED

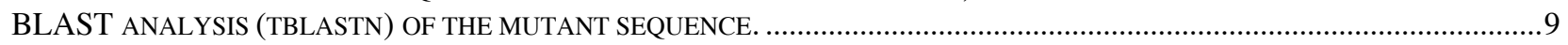

TRANSFECTION, STABLE TRANSFORMATION AND FOCI FORMATION OF 416 CELLS .................................9

TUMOR GROWTH OF 416 CELLS IN NORMAL AND ATHYMIC BALB/C MICE ..................................................10

AKT IMMUNOPRECIPITATION AND ANALYSIS FROM NIH 3T3, 416 AND 527 CELLS........................................10

\section{Media and Reagents}

Microbial media and reagents were prepared with standard recipes ${ }^{1}$ using HPLC grade water. $^{2} 2 \mathrm{xYT}$ is 17 g tryptone, ${ }^{3} 10$ g yeast extract, ${ }^{4} 5$ g sodium chloride ${ }^{5}$ in $1 \mathrm{~L}$ water. $2 \mathrm{xYT}-\mathrm{C}$ is

${ }^{1}$ Roskams, J.; Rodgers, L. Lab Ref: A Handbook of Recipes, Reagents, and Other Reference Tools

for Use at the Bench; Cold Spring Harbor Press: Cold Spring Harbor, 2002.

${ }^{2}$ Baker Analyzed ${ }^{\circledR}$ HPLC water, Cat. no. 4218-30, J.T. Baker, Inc., Phillipsburg, NJ, USA.

${ }^{3}$ Bacto $^{\text {TM }}$ Tryptone, Cat. no. 211705, Becton Dickinson \& Co., Sparks, MD, USA.

${ }^{4}$ Bacto $^{\mathrm{TM}}$ Yeast Extract, Cat. no. 212750 , Becton Dickinson \& Co., Sparks, MD, USA. 
2xYT with $50 \mu \mathrm{g} / \mathrm{mL}$ carbenicillin. ${ }^{6} \mathrm{NIH} 3 \mathrm{~T} 3$ and 527 mouse fibroblast cells were grown at $37{ }^{\circ} \mathrm{C}$ under a $5 \% \quad \mathrm{CO}_{2}$ atmosphere using standard techniques ${ }^{7}$ in medium consisting of $\mathrm{DMEM}^{8}$ supplemented with $10 \%$ fetal bovine serum, ${ }^{9} 100$ units $/ \mathrm{mL}$ penicillin and $100 \mu \mathrm{g} / \mathrm{mL}$ streptomycin. A stock solution of sodium orthovanadate ${ }^{10}(100 \mathrm{mM})$ was prepared as described. ${ }^{11}$ Enzymatic reactions were performed in non-DEPC treated nuclease free water, ${ }^{12}$ using standard protocols. ${ }^{13}$ Tris buffered saline (TBS) is $10 \mathrm{mM}$ Tris buffer, $\mathrm{pH} 7.0^{14}$ and $150 \mathrm{mM}$ sodium chloride. ${ }^{15}$ Phage wash buffer (PWB) is TBS with $0.05 \%$ Tween-20. Unless stated otherwise, all T7 phage-related protocols and manipulations including the generation and storage of phage lysate, selection, elution and titering of phage were performed as previously described. ${ }^{16,17}$ Phage were propagated by innoculation into log phase BLT5403 E. coli, ${ }^{18}$ cultured in 2xYT-C. LB media was used for top agarose and bottom agar. LB contains $10 \mathrm{~g}$ Bacto Tryptone, $5 \mathrm{~g}$ Bacto yeast extract and $5 \mathrm{~g} \mathrm{NaCl}$. LB bottom-agar contains LB and $15 \mathrm{~g}_{\text {agar }}{ }^{19}$ per liter of media. LB top-agarose contains LB and $6 \mathrm{~g}$ agarose $^{20}$ per liter of media. Bottom-agar plates are prepared in the usual manner. ${ }^{1}$ Top-agarose plates are prepared by pouring a freshly melted solution (cooled to $50{ }^{\circ} \mathrm{C}$ ) of previously autoclaved and aliquoted LB top-agarose containing $1 / 10$ volume of $E$. coli $\left(\mathrm{OD}_{600} 0.8-1.2\right) .{ }^{18}$ Phage-display affinity selections and binding studies were performed using Neutravidin ${ }^{\circledR}$-coated 96 -well ${ }^{21}$ or 8 well strip plates, ${ }^{22}$ Oligonucleotide synthesis and DNA sequencing was performed by the W. M. Keck Biotechnology Center at the Yale University School of Medicine. The oligonucleotide sequencing primers T7Forward (5'-TCTTCGCCCAGAAGCTGCAG) and T7Reverse (5'CCTCCTTTCAGCAAAAAACCCC) were used for both PCR amplification and DNA sequence analysis of the $\mathrm{T} 7$ phage-displayed inserts. ${ }^{23}$ Both blastn and blastp sequence comparisons of

\footnotetext{
${ }^{5}$ Sodium Chloride, Crystal, Cat. no. 3624-01, J.T. Baker, Phillipsburg, NJ, USA.

${ }^{6}$ Carbenicillin disodium salt, Cat. no. AB00285, American Bioanalytical, Inc., Natick, MA, USA.

${ }^{7}$ Freshney, R. I., Culture of Animal Cells: A Manual of Basic Technique. 3rd ed.; Wiley-Liss: New York, 1994; 486 pp.

${ }^{8}$ DMEM, Dulbecco's Modified Eagle's Medium, Cat. no. 1195-040, Gibco-BRL, Invitrogen, Inc.

${ }^{9}$ Fetal bovine serum, Cat no. 26140-095, Gibco-BRL, Invitrogen, Inc.

${ }^{10}$ Sodium orthovanadate, Cat. no. S6508, Sigma, Inc.

${ }^{11}$ Gordon, J. A. Methods Enzymol. 1991, 201, 477-82.

${ }^{12}$ Nuclease-free water (non-DEPC treated), Cat. no. 9932, Ambion, Inc., Austin, TX, USA.

${ }^{13}$ Sambrook, J.; Russel, D. W. Molecular Cloning: A Laboratory manual; 3rd ed.; Cold Spring

Harbor Laboratory Press: Cold Spring Harbor, 2001; Vol. 3.

${ }^{14}$ Diluted from 1M Tris (pH 7.0), Cat. no. 9851, Ambion, Inc., Austin, TX, USA.

${ }^{15}$ Aliquot from 5M NaCl, Cat. no. 9759, Ambion, Inc., Austin, TX, USA.

${ }^{16}$ Videlock, E. J.; Chung, V. K.; Mohan, M. A.; Strok, T. M.; Austin, D. J. J. Am. Chem. Soc. 2004, 126, 3730-1.

${ }^{17}$ T7Select $^{\circledR}$ System Manual, TB178 (Rev.B 02/03), Novagen, EMB Biosciences, Inc.

${ }^{18}$ BLT5403 glyceol stock, Cat. no. 69142-3, Novagen, EMB Biosciences, Inc.

${ }^{19}$ Agar, Bacteriological Grade, Cat. no. 10906, USB Corp., Cleveland, OH, USA.

${ }^{20}$ Agarose, Cat. no. 75817, USB Corp., Cleveland, OH, USA.

${ }^{21}$ High binding capacity Reacti-Bind ${ }^{\mathrm{TM}}$ NeutrAvidin ${ }^{\circledR}$ coated 96-well plates, Cat. no. 15507, Pierce Biotechnology, Rockford, IL, USA.

${ }^{22}$ High binding capacity Reacti-Bind ${ }^{\mathrm{TM}}$ NeutrAvidin $^{\circledR}$ coated 8-well strips, Cat. no. 15508, Pierce

Biotechnology, Rockford, IL, USA.

${ }^{23}$ The T7Forward and T7Reverse primer sequences were provided by Michael A. Tainsky and Fatima Nahhas at the Karmanos Cancer Institute, Wayne State University School of Medicine.
} 
affinity-selected genes were performed using the BLAST program ${ }^{24}$ against the NCBI Genbank nonredundant database. ${ }^{25}$ Statistical and non-linear regression analyses of titer data were performed using the GraphPad Prism program package. ${ }^{26}$

\section{General Experimental Methods}

\section{Preparation of $T 7$ cDNA-displaying phage lysate}

A general procedure for the preparation of T7 cDNA-displaying phage lysate for affinity selection is described. The preparation of phage lysate is identical for both cDNA libraries and individual phage clones. A $10 \mathrm{~mL}$ culture of BLT5403 E. coli is grown to saturation in $2 \mathrm{xYT}-\mathrm{C}$ overnight at $37^{\circ} \mathrm{C}$. A small aliquot of saturated cells are diluted to $10 \mathrm{~mL}\left(\mathrm{OD}_{600} 0.6-0.8\right)$ in $2 \mathrm{xYT}-\mathrm{C}$ and phage lysate (1- $10 \mu \mathrm{L}$, depending on desired MOI and phage titer of the inoculating solution) is added. When growing lysate from a single plaque, a sterile $10 \mu \mathrm{L}$ pipet tip is used to touch the plaque and then dropped into $1 \mathrm{~mL}$ of $\log$ phase $E$. coli. The cells are incubated at $37{ }^{\circ} \mathrm{C}$ until complete lysis is observed (between $45 \mathrm{~min}$. and 3 hours). Following lysis, the solution is centrifuged for either 10 minutes at $4700 \mathrm{rpm}$ in a Beckman GS-15R centrifuge, or 5 minutes at 14,000 rpm in an Eppendorf microcentrifuge, to remove cell debris.

\section{Preparation of affinity probe microtiter plates}

A general procedure for the preparation of Neutravidin ${ }^{\circledR}$-coated microtiter plates with biotinylated affinity probe is described. An avidin microtiter plate is incubated with $100 \mu \mathrm{L}$ of a biotin-probe solution for $1-2$ hours at $37{ }^{\circ} \mathrm{C}$ or overnight at $4{ }^{\circ} \mathrm{C}$. After probe incubation, the well(s) are washed with TBS $(1 \times 200 \mu \mathrm{L})$ and incubated with $200 \mu \mathrm{L}$ of $1 \mathrm{mM}$ biotin at $37^{\circ} \mathrm{C}$ for 1 hour. This step is a biotin block that reduces background binding by blocking excess biotin binding sites on avidin. The well(s) are washed with TBS $(3 \times 200 \mu \mathrm{L})$ to remove excess biotin. At this point the probe well(s) can be used immediately or stored at $4{ }^{\circ} \mathrm{C}$ in TBS until needed, usually within 24 hours.

\section{Affinity selection with T7 cDNA-displaying phage}

A general protocol for the affinity assay of cDNA-displaying T7 phage in a 96-well microtiter plate is described. Freshly prepared T7 phage lysate $(200 \mu \mathrm{L})$ is pre-cleared by incubation in an untreated Neutravidin $^{\circledR}$-coated microtiter plate for 1 hour at room temperature. A portion of the phage solution $(100 \mu \mathrm{L})$ is then diluted to $0.05 \%$ Tween- 20 and transferred to a probe-treated microtiter plate. The solution is then incubated for either four hours at room temperature or overnight at $4{ }^{\circ} \mathrm{C}$. After incubation, the plate is washed 1 - 5 times with 2 xYT $(200 \mu \mathrm{L})$. Bound phage are removed by either direct $E$. coli infection or treatment with 1\% SDS (both described below).

\section{E. coli elution of affinity clones}

Direct infection of bound phage can be achieved by adding log phase E. coli to the selection well. This protocol is the elution method of choice when propagating phage from one selection round to the next. In this manner, $100 \mu \mathrm{L}$ of BLT5403 $\left(\mathrm{OD}_{600} 0.6-0.8\right)$ in $2 \mathrm{xYT}-\mathrm{C}$ is added to the selection well and allowed to incubate for 10 minutes at room temperature. The solution is then removed (E1 elution), before lysis takes place, at which time an additional $100 \mu \mathrm{L}$ of $E$. coli is added to the well (E2 elution). This process may be repeated as often as desired, we have performed up to six consecutive E. coli elutions. Each resulting elution is separately incubated at $37^{\circ} \mathrm{C}$ until complete lysis is observed (between $45 \mathrm{~min}$. and 3 hours).

\footnotetext{
${ }^{24}$ Altschul, S.F.; Gish, W.; Miller, W.; Myers, E.W.; Lipman, D.J. J. Mol. Biol. 1990, 215, 403-10.

${ }^{25}$ National Center for Biotechnology Information (NCBI), BLAST Homepage, http://www.ncbi.nlm.nih.gov/BLAST/.

${ }^{26}$ GraphPad Prism version 4.0a for Mac OS X, GraphPad Software, San Diego, CA, USA. 


\section{SDS elution of affinity clones}

To remove surface bound phage in a non-specific manner, bound phage are treated with a denaturant. This protocol is the elution method of choice for dose-dependent binding studies. In this manner, $100 \mu \mathrm{L}$ of a $1 \%$ SDS solution ${ }^{27}$ is added to the selection well and allowed to incubate for 30 minutes at room temperature. The solution is pipetted up and down several times before removal. The resulting solution may be titered directly (as described below) or used for phage propagation after either 200-fold dilution or SDS crystalization (overnight at $4{ }^{\circ} \mathrm{C}$ ).

\section{Titering phage solutions}

The following is a general protocol for quantifying phage solutions in a 96-well plate format. Tenfold serial dilutions are made in a disposable 96 -well plate ${ }^{28}$ by transferring $10 \mu \mathrm{L}$ of phage solution from one well to the next, then diluting with $90 \mu \mathrm{L}$ of $2 x \mathrm{YT}^{29}$ This process is repeated six times, filling one half of the plate. In this manner 16 different phage solutions can be serially diluted on one 96-well plate. Using a multi-channel pipettor, the serially diluted solutions are dropped in rows of 8 ( $2 \mu \mathrm{L}$ each) onto freshly prepared top-agarose plates (E. coli infected $2 x Y T$ top-agarose poured onto $2 \mathrm{xYT}$ bottom-agar plates). ${ }^{30}$ Each dilution is dropped in triplicate, the plate is allowed to air dry, then inverted and incubated at $37{ }^{\circ} \mathrm{C}$ until plaques are noticeable (approximately $2-3$ hours). Alternatively, the plates may be incubated at room temperature overnight. After incubation, each dropped dilution on the plate will appear as a circle composed of either a single plaque covering the entire circular area (at the higher concentrations) or individual plaques contained within the circular drop area (at the lower concentrations). Phage counts are made from dilution drops containing between 5 and 50 individual plaques. The phage titer is calculated by multiplying the observed number of plaques by the order of the dilution (taking into account the volume of the original solution and the drop size).

\section{PCR amplification of $c D N A$ inserts}

Phage clones selected for DNA sequencing were first subjected to PCR amplification of the insert region using the T7Forward and T7Reverse primers (described in Media and Reagents). DNA sequencing of the PCR amplified band, following reaction clean-up, ${ }^{31}$ yields much more consistent and longer sequencing reads. In a typical PCR reaction $1 \mu \mathrm{L}$ of crude phage lysate can be directly substituted for template DNA. The thermal cycling protocol includes a preliminary incubation step $\left(94{ }^{\circ} \mathrm{C}, 2 \mathrm{~m} 30 \mathrm{~s}\right)$, which helps to denature the phage coat, followed by thirty-five cycles of denaturation $\left(94^{\circ} \mathrm{C}, 45 \mathrm{~s}\right)$, annealing $\left(58^{\circ} \mathrm{C}, 60 \mathrm{~s}\right)$ and extension $\left(72{ }^{\circ} \mathrm{C}, 30 \mathrm{~s}\right)$, which is in turn followed by a long extension step $\left(72{ }^{\circ} \mathrm{C}, 10 \mathrm{~m}\right)$ and a $4{ }^{\circ} \mathrm{C}$ hold. If longer inserts are anticipated, then modifications to the extension time $(1 \mathrm{~min} / \mathrm{Kbp})$ can be made. In addition the annealing temperature can be lowered to $50^{\circ} \mathrm{C}$, but $55-58{ }^{\circ} \mathrm{C}$ is a good working range for these primers.

${ }^{27}$ Ten-fold TBS dilution of sodium dodecyl sulfate, 10\% solution, Cat. no. 9822, Ambion, Inc., Austin, TX, USA.

${ }^{28}$ Flexible Plate, 96 Well, U-Bottom without Lid, Falcon, cat no. 353911, Becton Dickinson \& Co., Franklin Lakes, NJ, USA.

${ }^{29}$ Growth media (2xYT) is used for serial dilutions since it has been observed (data not shown) that T7 phages are more stable when stored in media (such as 2xYT), rather than buffer (such as TBS).

${ }^{30}$ Square plates allow up to eight rows of $2 \mu \mathrm{L}$ aliquots to be dropped on each plate when using an eight channel pipetor; Sterile Disposable Petri Dish, Square, 100 x 15mm, Fisherbrand, Cat. no. 08757-11A, Fisher Scientific, Agawam, MA, USA.

${ }^{31}$ QIAquick PCR Purification Kit, Cat. no. 28104, Qiagen, Inc., Valencia, CA, USA. 


\section{cDNA Phage Display Selection with the bio-pYTAR Peptide Probe}

Synthesis of the bio-pYTAR peptide was performed using fmoc chemistry on a Rainin Symphony automated synthesizer. ${ }^{32}$ A single well of a Neutravidin ${ }^{\circledR}$-coated plate was incubated with $100 \mu \mathrm{L}$ of a $10 \mu \mathrm{M}$ bio-pYTAR solution for 1 hour at $37^{\circ} \mathrm{C}$, washed with $200 \mu \mathrm{L}$ of 1 xTBS and incubated with $1 \mathrm{mM}$ biotin for an additional $30 \mathrm{~min}$ at $37^{\circ} \mathrm{C}$. A $100 \mu \mathrm{L}$ aliquot of a human liver T7 cDNA phage library $^{33}$ (containing $0.05 \%$ Tween-20) was allowed to incubate for 1 hour with an untreated avidin plate for pre-clearing, then transferred to a probe-treated plate and allowed to incubate overnight at 4 ${ }^{\circ} \mathrm{C}$. The plate was then washed with 2 xYT $(3 \times 200 \mu \mathrm{L})$. Bound phage were eluted by addition of $100 \mu \mathrm{L}$ of $\log$ phase BLT5403 E. coli and incubation at room temperature for 10 minutes. After removal of the first $E$. coli solution, a second incubation with $E$. coli was performed for an additional 10 minutes. Both solutions were incubated separately at $37^{\circ} \mathrm{C}$ until lysis was observed. The lysates were then combined, centrifuged at $14,000 \mathrm{rpm}$ for 5 minutes to remove cell debris and used directly in the next selection round. This cycle was repeated for three rounds. After the third affinity selection, bound phage were eluted by addition of $100 \mu \mathrm{L}$ of a $1 \%$ SDS solution for 30 minutes at room temperature. The resulting phage solution was diluted and a $2 \mu \mathrm{L}$ aliquot from each dilution was dropped onto an $E$. coli containing top-agarose plate so that individual phage plaques could be identified.

\section{Screening and Validation of Phage from the bio-pYTAR Affinity Selection.}

Forty-eight individual plaques from the third selection round were randomly selected and used to inoculate log phase BLT5403 E. coli, each in its own falcon tube, and incubated at $37{ }^{\circ} \mathrm{C}$ until lysis was observed. The phage lysate was then centrifuged at $14,000 \mathrm{rpm}$ for 10 minutes in order to remove cell debris. Each of the individual phage lysate solutions were transferred to a single well of a probe-treated 96-well plate and incubated for four hours at room temperature. The lysate was removed and the wells were washed 5 times with $200 \mu \mathrm{L} 2 \mathrm{xYT}$. The remaining phage were

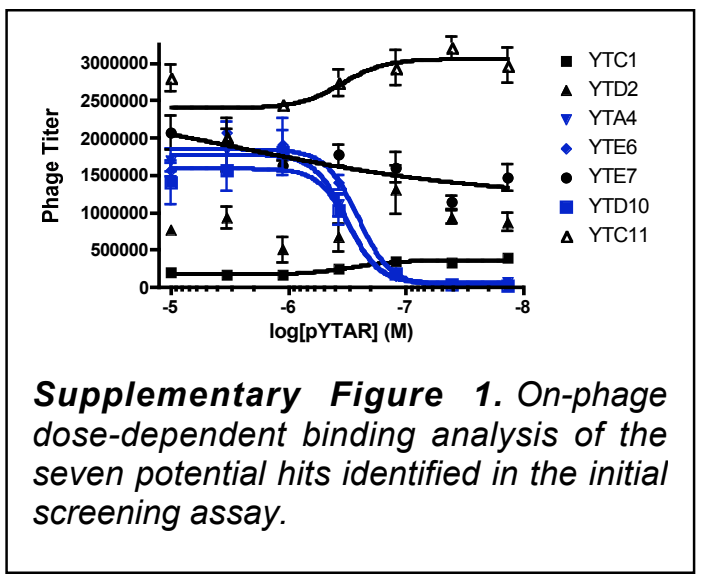
eluted by treatment with $100 \mu \mathrm{L}$ of a $1 \%$ SDS solution for 30 minutes at room temperature. The resulting phage solutions were serially diluted in 96-well plates and $2 \mu \mathrm{L}$ aliquots of each dilution was dropped in triplicate onto $E$. coli containing top-agarose plates. Of the clones evaluated, seven phage clones showed good affinity for the probe-treated plate (YTC1, YTD2, YTA4, YTE6, YTE7, YTD10 \&YTC11), while the remaining clones showed no appreciable affinity for the probe over background levels. In order to evaluate whether these seven phage contain cDNA inserts that encode for proteins with probe-dependent binding, lysate from each clone was incubated in a series of seven wells, each treated with a serial dilution of bio-pYTAR affinity probe (Supplementary Figure 1) and titered (as described in General Experimental Methods). Clones YTE7 and YTC11, which bind with high titer, actually exhibit no probe dependence. In addition, neither of the clones YTC1 or

\footnotetext{
${ }^{32}$ W. M. Keck Biotechnology Center, Yale University School of Medicine.

${ }^{33}$ T7Select $^{\circledR}$ Human Liver cDNA Phage Display Library, cat no. 70641-3, lot no. N30898, Novagen, EMB Biosciences, Inc.
} 
YTD2 showed any appreciable affinity on re-evaluation. However, three clones, YTA4, YTE6 and YTD10 exhibited reproducible affinity, in a dose-dependent manner and were further evaluated.

\section{Sequence Identification of the p85 PI3K N-terminal SH2 cDNA Phage Clone}

In order to identify the protein sequence encoded in the three binding phage clones (YTA4, YTE6 \& YTD10), their cDNA inserts were subjected to DNA sequence analysis. Amplified lysates were prepared from individual plaques (as described in General Experimental Methods) and the cDNA insert region of the T7 phage genome was amplified by PCR using T7Forward and T7Reverse oligonucleotide primers. The amplified DNA was purified and submitted for DNA sequencing with the T7Forward primer, which provides sequence information from the 5'-end of the cloned cDNA insert. All three clones were found to be identical and contain a segment of DNA that encodes the N-terminal SH2 domain of the p85 regulatory subunit of phosphatidyinositol-3 kinase (PI3K). ${ }^{34}$ Dual strand sequence verification of the clone described in this paper is shown in Supplementary Figure 2.

Supplementary Figure 2. DNA sequence verification for p85 PI3K N-terminal SH2 phage clone.

\begin{tabular}{|c|c|c|c|c|c|c|c|c|c|c|c|c|c|c|c|c|}
\hline $\mathrm{CA}$ & $\mathrm{GT}$ & & & & & & & & & TCA & & & & & & \\
\hline$A A$ & $\mathrm{CCA}$ & $\mathrm{CA}$ & AAA & $\mathrm{CCT}$ & $\mathrm{ACT}$ & $\mathrm{CT}$ & GTA & $\mathrm{GC} \overline{\mathrm{C}}$ & $\mathrm{AAC}$ & $\overline{\mathrm{AA} C}$ & GT & TG & & & & \\
\hline & TA & & $\mathrm{AT}$ & $\mathrm{GCT}$ & GAA & GG & TAC & TGG & GGA & GAT & ATC & CG & GG & & & \\
\hline & $A \mathrm{~A}$ & 7 & ГT & CGA & AT & CA & $C A$ & $\mathrm{AC}$ & GGG & $\mathrm{ACC}$ & TT & TG & TA & GA & $\mathrm{AT}$ & \\
\hline & $\mathrm{CT}$ & & TG & $\mathrm{AT}$ & GT & $\mathrm{AT}$ & $\mathrm{AT}$ & CT & СтT & $\mathrm{ACA}$ & TA & GG & $\mathrm{AA}$ & & & \\
\hline & & & ГC & $A \mathrm{~A}$ & $\Gamma \mathrm{A}$ & $\Gamma \mathrm{T}$ & $\mathrm{AT}$ & $\mathrm{GA}$ & GAT & GGG & $\mathrm{AA}$ & $\mathrm{AT}$ & GC & एC & & \\
\hline & & & ГC & GT & 'СT & TG & ГT & $A A$ & TTA & ATA & $\mathrm{AC}$ & $A C$ & $\mathrm{AC}$ & & & \\
\hline & & & & $\mathrm{AT}$ & $\mathrm{AT}$ & & & & GAT & GTG & $\mathrm{AA}$ & & TT & & & \\
\hline & & & & & & & & & $A A A$ & GAA & & & & & & \\
\hline & & & & & & & & & GT & $\mathrm{CA}$ & & & & & & \\
\hline
\end{tabular}

The N-SH2 PI3K clone sequence data (Supplementary Figure 2) shows T7 genomic DNA on the $5^{\prime}$ and $3^{\prime}$ end of the insert region (normal black font), with the 5' sequence encoding the Cterminal peptide sequence of the cp10 coat protein, and both the EcoR I and Hind III restriction sites, which were used to construct the cDNA library can be seen flanking the insert (blue bold underlined font). The DNA sequence that matches the PI3K mRNA is shown in green and red font, with bold green font representing the DNA sequence of the $\mathrm{SH} 2$ domain. It should be noted that the reading frame for the insert is in-frame with the reading frame of the cp10 coat protein, which is required for proper translation of the viral fusion protein. Interestingly, this sequence does contain an extra $G$ base pair (bold red), which causes a frame-shift mutation (red font) and early STOP signal (bold red underlined font). This mutation was likely introduced during the cDNA synthesis, however, since it occurs after the SH2 domain gene sequence, it does not interfere with expression of the intact $\mathrm{SH} 2$.

\section{pYTAR Probe Dependent Phage Binding Assay and Inhibition with pYVPM}

Consecutive wells of a Neutravidin ${ }^{\circledR}$-coated 96-well strip plate were incubated for one hour at $37{ }^{\circ} \mathrm{C}$ with $100 \mu \mathrm{L}$ aliquots of serially diluted bio-pYTAR probe $(2 \mu \mathrm{M}$ starting concentration with 3/4-volume serial dilutions). The wells were then washed with TBS (1x200 $\mu \mathrm{L})$ and blocked with $1 \mathrm{mM}$ biotin $(200 \mu \mathrm{L})$ for 1 hour at $37{ }^{\circ} \mathrm{C}$. The biotin solution was removed and the wells washed again with TBS $(3 \times 200 \mu \mathrm{L})$. Phage lysate from a stock solution of p $85 \alpha$ PI3K phage was generated from a log phase BLT5403 E. coli and spun at 14,000 rpm to remove residual cell debris.

\footnotetext{
${ }^{34}$ PI3K p85 $\alpha$ subunit, NM_181523, Homo sapiens phosphoinositide-3-kinase, regulatory subunit, polypeptide 1 (p85 alpha) (PIK3R1), mRNA.
} 
One aliquot was treated with $100 \mu \mathrm{M}$ pYVPM peptide inhibitor ${ }^{35}$ for one hour, while a second aliquot was remained untreated. Both aliquots were incubated with the pYTAR probe plate at $4{ }^{\circ} \mathrm{C}$ overnight. Each experiment, both treated and untreated phage lysate, was performed in triplicate. After incubation, unbound phage was removed by washing with $200 \mu \mathrm{L}$ PWB $(10 \times 200 \mu \mathrm{L})$. The remaining phage were eluted from the plate by incubation with $1 \%$ SDS $(100 \mu \mathrm{L})$ at room temperature for 30 minutes. The phage were then titered (as described above) and plotted as a function of incubated bio-pYTAR probe concentration.

In order to estimate an $\mathrm{EC}_{50}$ value for the bio-pYTAR probe with the p85 PI3K N-SH2 phage, the titer data was subjected to non-linear regression analysis using a variable-slope sigmoid dose response model based on the following equation: ${ }^{36}$

$$
Y=B+\frac{(T-B)}{\left(1+10^{\left(\left(\log E C_{50}-X\right) \times H S\right)}\right)}
$$

Where $\mathrm{X}$ is the logarithm of the probe concentration used to incubate the plate, $\mathrm{Y}$ is the observed phage titer, $B$ is the minimum data value, $T$ is the maximum data value and HS is the Hill Slope. This equation is applied with the assumption that $\mathrm{Y}$ starts at $\mathrm{B}$ (the bottom) bottom and proceeds to $\mathrm{T}$ (the top) through a sigmoid shaped curve, also known as the four parameter logistic equation or variable slope sigmoid equation. ${ }^{37}$ Results of the data analysis are shown in Supplementary Table 1.

Supplementary Table 1. Parameter values computed from the bio-pYTAR probe-dependent binding assay for the p85 PI3K N-terminal SH2 domain phage.

\begin{tabular}{|l|l|}
\hline Best-Fit Values & \multicolumn{1}{|c|}{ p85 PI3K/pYTAR } \\
\hline Bottom & $1.0 \times 10^{-7}$ \\
\hline Top & $2.27 \times 10^{6}$ \\
\hline LogEC $_{50}$ & -6.68 \\
\hline Hillslope & 2.04 \\
\hline EC $_{50}$ & $2.07 \times 10^{-7}$ \\
\hline Std. Error & \\
\hline LogEC $_{50}$ & 0.03326 \\
\hline Hillslope & 0.2949 \\
\hline 95\% Confidence Interval $^{-7}$ & \\
\hline LogEC $_{50}$ & -6.749 to -6.619 \\
\hline Hillslope & 1.464 to 2.621 \\
\hline EC & $1.78 \times 10^{-7}$ to $2.40 \times 10^{-7}$ \\
\hline Goodness Of Fit & \\
\hline Degrees Of Freedom & 149 \\
\hline R Squared & 0.8602 \\
\hline Absolute Sum Of Squares & $1.92 \times 10^{13}$ \\
\hline Sy.X & 359081 \\
\hline Constraints & \\
\hline Bottom & $>0.0$ \\
\hline Top & none \\
\hline Number Of X Values & 16 \\
\hline Number Of Y Replicates & 12 \\
\hline & \\
\hline
\end{tabular}

${ }^{35}$ Acetyl-DpYVPML-NH 2 , cat no. 151-027-M001, Alexis Biochemicals, San Diego, CA, USA.

${ }^{36}$ Non-linear regression analysis was performed using GraphPad Prism version 4.0a for Mac OS X, GraphPad Software, San Diego, CA, USA.

${ }^{37}$ Motulsky, H. J.; Christopoulus, A. Fitting models to biological data using linear and non-linear regression. A practical guide to curve fitting.; GraphPad Software, Inc.: San Diego, 2003. 


\section{Peptide Affinity Chromatography with bio-pYTAR and NIH 3T3 Cell Lysate}

The protocol for preparation of cell lysate was adapted from that of Bachelot et al. ${ }^{38} \mathrm{~A} 100 \mathrm{~mm}$ plate of NIH 3T3 cells (90-100\% confluence) were washed with ice cold TBS (3x15 mL) and treated with $350 \mu \mathrm{L}$ 1xRIPA-V/P ${ }^{39}$ (50 mM Tris-HCl, pH 7.4, $150 \mathrm{mM} \mathrm{NaCl}, 0.25 \%$ deoxycholic acid, 1\% NP40, $1 \mathrm{mM}$ EDTA, $10 \mathrm{mM} \mathrm{Na} 2 \mathrm{VO}_{4}, 1.04 \mathrm{mM}$ AEBSF, $800 \mathrm{nM}$ aprotinin, $20 \mu \mathrm{M}$ leupeptin, $40 \mu \mathrm{M}$ bestatin, $15 \mu \mathrm{M}$ pepstatin A, $14 \mu \mathrm{M}$ E-640). The cells were scraped, transferred to a Dounce homogenizer, plunged twenty times and allowed to incubate at $4{ }^{\circ} \mathrm{C}$ for 45 minutes. After spinning to remove cell debris (14,000 rpm for 15 minutes) the lysate was filtered (2.5 micron filter) to yield approximatey $300 \mu \mathrm{L}$ of lysate with a protein concentration of $2.5 \mathrm{mg} / \mathrm{mL}$. The lysate was precleared by incubation with $500 \mathrm{~mL}$ Neutravidin ${ }^{\circledR}$-coated resin for 1 hour at $4{ }^{\circ} \mathrm{C}$ prior to treatment with probe. Three aliquots of the lysate was made, and individually treated with either $100 \mathrm{mM}$ biopYTAR peptide, buffer alone, or $100 \mathrm{mM}$ bio-pYTAR peptide and $100 \mathrm{mM}$ bio-pYVPM inhibitor peptide. The solutions were incubated at $4{ }^{\circ} \mathrm{C}$ for 45 minutes prior to the addition of $500 \mathrm{~mL}$ Neutravidin ${ }^{\circledR}$ resin and incubation overnight at $4{ }^{\circ} \mathrm{C}$. After incubation, the resins were washed with TBS $(5 \times 750 \mathrm{~mL})$, boiled in $500 \mathrm{~mL}$ Laemmli buffer and concentrated using a 50 kiloDalton molecular weight cut-off spin column. ${ }^{40}$ The resulting protein solutions were subjected to SDSPAGE and Western blot analysis using an anti-PI3K antibody, ${ }^{41}$ followed by chemiluminescent detection with a goat anti-mouse HRP-conjugated antibody. ${ }^{42}$ Data is shown in Figure 2 of the manuscript.

\section{Co-immunoprecipitation and inhibition of Src binding with $\alpha$-PI3K Antibody}

Generation of lysate from was performed, as described above, from four $100 \mathrm{~mm}$ plates of 527 cells (90\% confluent) using $1 \times$ RIPA-V/P buffer. Lysate from one additional plate of 527 cells was prepared with 1xRIPA-P, without the addition of sodium orthovanadate. Two $300 \mu \mathrm{L}$ aliquots of vanadate-treated lysate were incubated with either buffer alone or $100 \mu \mathrm{M}$ pYVPM, while a $300 \mu \mathrm{L}$ aliquot of vanadate-untreated lysate was incubated with 300 units of Yersinia pestis tyrosine phosphatase (YOP) on ice for 3 hours. All three lysate solutions were then incubated with $20 \mu \mathrm{L}$ anti-PI3K antibody agarose ${ }^{43}$ overnight at $4{ }^{\circ} \mathrm{C}$. After incubation, the resins were washed with TBS $(5 \times 750 \mu \mathrm{L})$, boiled in $500 \mu \mathrm{L}$ Laemmli buffer to remove bound protein. The resulting immunoprecipitates were then subjected to SDS-PAGE and visualized by Western blot analysis with a mouse anti-Src monoclonal antibody ${ }^{44}$ and a mouse anti-PI3K monoclonal antibody, ${ }^{45}$ followed by chemiluminescent detection with a goat anti-mouse HRP-conjugated antibody. ${ }^{42}$ Data is shown in Figure 3 of the manuscript.

\footnotetext{
${ }^{38}$ Procedure for cell lysis adapted from: Bachelot, C.; Rameh, L.; Parsons, T.; Cantley, L. C. Biochimica et Biophysica Acta. 1996, 1311, 45-52.

${ }^{39} 1 x$ RIPA-VP is made from 10xRIPA, Cat. no. 20-188, Upstate, Inc., a $100 \mathrm{mM}$ sodium orthovanadate stock solution (V) and Protease Inhibitor Cocktail (P), Cat. no. P8340, Sigma, Inc.

40 50KD NMWL, Cat. no. UFV5BQ25, Millipore, Inc.

${ }^{41}$ Anti-PI3 Kinase p85, N-SH2, clone UB93-3, Cat. no. 05-217, Upstate Biotechnology, Inc.

${ }^{42}$ Goat anti-mouse IgG HRP-conjugate, Cat. no. 12-349, Upstate Biotechnology, Inc.

${ }^{43}$ Anti-PI3 Kinase, p85, agarose conjugate, Cat. no. 16-107, Upstate Biotechnology, Inc.

${ }^{44}$ Anti-Src, GD11, Cat. no. 05-184, Upstate Biotechnology, Inc.

${ }^{45}$ Anti-PI3 Kinase p85, N-SH3, clone AB6, Cat. no. 05-212, Upstate Biotechnology, Inc.
} 


\section{Mutagenesis of Src-Y527F to form the Src-Y416F,Y527F double mutant}

The Y416F,527F double mutant was created from an activated Src (Y527F) cDNA in the pUSEAmp plasmid, ${ }^{46}$ using QuickChange mutagenesis ${ }^{47}$ with the primers 5 NSRCYF $\left(5^{\prime}\right.$-GACTTTGGGCTGG CTCGGCTCATTGAGGACAATGAGTTCACGGCGCGGCAAGGTGCCAAATTCCC-3') and 3NSRCYF (5'-GGGAATTTGGCACCTTGCCGCGCCGTGAACTCATTGTCCTCAATGAGCCG AGCCAGCCCAAAGTC-3'), each having an estimated annealing temperature of $92{ }^{\circ} \mathrm{C}$. The mutagenesis was performed as described in the standard protocol, except that 18 cycles were used and the duration of each cycle extension was 16 minutes. In addition to introducing the Y416F mutation, one of two Bbs I restriction endonuclease sites in the pUSEamp plasmid was also removed in order to facilitate rapid analysis of mutated plasmids over wild type plasmids. The SrcY416F,Y527F double mutant was verified by sequencing the mutated plasmid with the primer 5SRCSEQ1 (5'-GGCGTACGTGGAGCGGATGAACTA-3'), which anneals to a site ?? base pairs preceding the mutation site. A translated BLAST (tblastn) sequence search of the Src-Y416F, Y527F double mutant (VCHU-V416F03-5SrcSq1_054) returned the Src gene sequence with a Y416F mutation (Supplementary Figure 3). This sequence analysis also showed the 527 mutation from the initial commercial plasmid (data not shown).

Supplementary Figure 3. Sequence verification of the Src-Y416F,Y527F double mutant. Translated BLAST analysis (tblastn) of the mutant sequence.

Src-416F,527F: LVCKVADFGLARLIEDNEFTARQGAKFPIKWTAPEAALYGRFTIKSDVWSFG LVCKVADFGLARLIEDNE+TARQGAKFPIKWTAPEAALYGRFTIKSDVWSFG

Src (wild type): LVCKVADFGLARLIEDNEYTARQGAKFPIKWTAPEAALYGRFTIKSDVWSFG

\section{Transfection, stable transformation and foci formation of $\mathbf{4 1 6}$ cells}

The Src-Y416F,Y527F plasmid was transfected into NIH 3T3 cells using the Lipofectamine 2000 reagent $^{48}$ using the recommended procedure. ${ }^{49}$ A 100 $\mathrm{mm}$ plate of NIH $3 \mathrm{~T} 3$ cells was treated with $5 \mu \mathrm{g}$ of plasmid DNA in $32 \mu \mathrm{L}$ of Lipofectamine 2000 in $5 \mathrm{~mL}$ of serum free media (DMEM with $1 \%$ penicillin/streptomycin; $1 \%$ L-Glutamine) at $37{ }^{\circ} \mathrm{C}$. After three hours, $5 \mathrm{~mL}$ of media containing $20 \%$ calf serum was added. The cells were allowed to incubate at $37^{\circ} \mathrm{C}$ for an additional twenty hours, after which they were split $1: 2$ into media containing $0.75 \mathrm{mg} / \mathrm{mL}$ and allowed to grow until focus formation was observed (approximately six weeks). A single focus was picked, treated with trypsin, re-plated and propagated as a clonal cell line. This cell line was named 416 and used in the experiments described below.

\footnotetext{
${ }^{46}$ Src-Y527F(cDNA), in pUSEamp vector, Cat. no. 21-115, Upstate Biotechnology, Inc.

${ }^{47}$ QuickChange II XL mutagenesis kit, Cat no. 200521, Stratagene, Inc.

${ }^{48}$ Lipofectamine 2000 Reagent, Cat. no. 11668, Life Technologies, Inc.

${ }^{49}$ Ciccarone, V.; Chu, Y.; Schifferli, K.; Pichet, J.-P.; Hawley-Nelson, P.; Evans, K.; Roy, L.; Bennett, S., Lipofectamine 2000 reagent for rapid, efficient transfection of eukaryotic cells. Focus 1999, 21, 54-5.
} 


\section{Tumor growth of 416 cells in normal and athymic BALB/c mice}

A single injection of $0.5 \times 10^{6}$ cells was performed subcutaneously in the right flank of five normal BALB/c mice (BALB/cAnNTac) and five athymic BALB/c mice $\left(\right.$ BALB/cAnNTac-Foxn ${ }^{\text {nu/nu }}$ N9) ${ }^{50}$ After five weeks, all five athymic mice showed tumors, while none of the normal mice showed any sign of tumor growth as of 8 weeks post-injection. In comparison, a similar injection of the 527 cell line $\left(0.5 \times 10^{6}\right.$ cells $)$, performed at the same time, caused tumor formation in both normal and athymic BALB/c mice within three weeks.

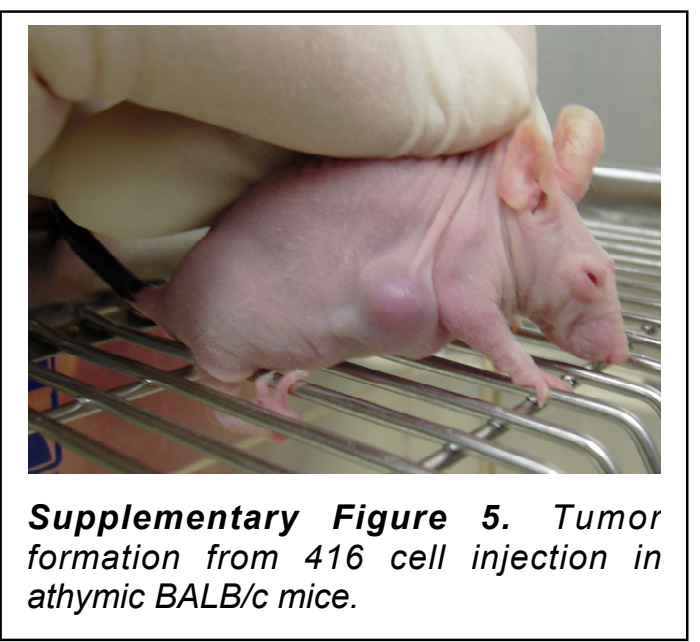

\section{Akt Immunoprecipitation and analysis from NIH 3T3, 416 and 527 cells}

Cell lysate from the 527 and 416 cell lines, along with the parent NIH 3T3 cell line was obtained from confluent $100-\mathrm{mm}$ plates using a tyrosine and serine/threonine phosphatase inhibitor containing lysis buffer. ${ }^{51}$ The lysates were normalized for total protein and a $200 \mu \mathrm{L}$ aliquot was treated with 4 $\mu \mathrm{L}$ of $\alpha$-AKT antibody ${ }^{52}$ and incubated overnight at $4{ }^{\circ} \mathrm{C}$. Each aliquot was treated with protein $\mathrm{A}$ agarose $\left(50 \%\right.$ slurry) and incubated for five hours at $4{ }^{\circ} \mathrm{C}$. The agarose resin was centrifuged briefly, the supernatant discarded, and the resin washed five times with $150 \mu \mathrm{L}$ of lysis buffer. The excess buffer was removed and the resin was treated with $75 \mu \mathrm{L}$ of Laemmli buffer containing bmercaptothiol and boiled for five minutes, with gentle agitation after three minutes. The resin was centrifuged briefly and the supernatant removed and two 10\% SDS-polyacrylamide gels were loaded identically and run, followed by blotting onto a nitrocellulose membrane. One gel was treated with an $\alpha$-rabbit-HRP IgG antibody ${ }^{53}$ in order to evaluate gel loading. The second gel was treated with an HRP-conjugated $\alpha$-phosphotyrosine antibody cocktail. ${ }^{54}$ Both blots were developed by chemiluminescence and are shown in Figure 4 of the manuscript.

\footnotetext{
${ }^{50}$ Mice purchased from Taconic Labs, Inc.

${ }^{51}$ PhosphoSafe $^{\mathrm{TM}}$ Extraction Buffer, Cat no. 71296, EMD/Novagen, Inc.

${ }^{52}$ Akt Antibody (rabbit), Cat. no. 9272, Cell Signaling, Inc.

${ }^{53}$ Anti-Rabbit IgG AP-liked Antibody, Cat no. 7054, Cell Signaling, Inc.

${ }^{54}$ Py-Plus-HRP Mouse anti-Phosphotyrosine (Cocktail), Cat no. 13-6620, Zymed Laboratories, Inc.
} 